\title{
Gilles Gagné, Jean-Philippe Warren (a cura di) Sociologie et valeurs: quatorze penseurs québécois du $\mathrm{XX}$ siècle
}

\section{Simona Rossi}

\section{(2) OpenEdition \\ 1 Journals}

\section{Edizione digitale}

URL: http://journals.openedition.org/studifrancesi/33788

DOI: $10.4000 /$ studifrancesi.33788

ISSN: 2421-5856

\section{Editore}

Rosenberg \& Sellier

\section{Edizione cartacea}

Data di pubblicazione: 1 décembre 2005

Paginazione: 684-685

ISSN: 0039-2944

\section{Notizia bibliografica digitale}

Simona Rossi, «Gilles Gagné, Jean-Philippe Warren (a cura di) Sociologie et valeurs: quatorze penseurs québécois du XXe siècle», Studi Francesi [Online], 147 (XLX | III) | 2005, online dal 30 novembre 2015, consultato il 18 avril 2021. URL: http://journals.openedition.org/studifrancesi/33788 ; DOI: https:// doi.org/10.4000/studifrancesi.33788

Questo documento è stato generato automaticamente il 18 avril 2021.

\section{cc) $(9)$}

Studi Francesi è distribuita con Licenza Creative Commons Attribuzione - Non commerciale - Non opere derivate 4.0 Internazionale. 


\title{
Gilles Gagné, Jean-Philippe Warren (a cura di) Sociologie et valeurs: quatorze penseurs québécois $d u X^{\mathrm{e}}$ siècle
}

\author{
Simona Rossi
}

\section{NOTIZIA}

GILLES GAGNÉ,JEAN-PHILIPPE WARREN (a cura di) Sociologie et valeurs: quatorze penseurs québécois du XXe siècle, Montréal, Les presses de l'Université de Montréal, 2003, pp. 393.

1 Questo testo, che raggruppa le riflessioni di quattordici sociologi quebecchesi, mira a dimostrare quanto la sociologia costituisca uno strumento prezioso per lo studio dei popoli e in particolare di quello quebecchese, qui preso in esame. Oggetto d'indagine dei quattordici saggi è il XX secolo, un periodo estremamente complesso, ma anche molto stimolante, caratterizzato da diversi fattori: la crescente modernizzazione, il forte accentramento identitario, l'esplosione dell'urbanizzazione, l'immigrazione dilagante... Gli autori si sforzano di andare al di là della pura analisi scientifica e di offrire ai lettori un quadro d'insieme chiaro e preciso dei "fatti e valori" più significativi del XX secolo, sui quali la sociologia ha potuto riflettere. Tale sforzo ha preso forme e prospettive molto diverse tra loro, ma ugualmente interessanti: Léon Gérin introduce la materia, spiegando la "volgarizzazione" delle scienze sociali in Canada; Édouard Montpetit e Marc Renaud si addentrano nel difficile territorio dell'insegnamento universitario, chiarendo le problematiche più attuali e i cambiamenti più recenti; Arthur Robert stabilisce un parallelo davvero innovativo tra morale e sociologia; Esdras Minville illustra alcuni risvolti sociologici dell'economia politica; Georges-Henri Lévesque, Jean-Charles Falardeau e Guy Rocher mostrano l'importanza del contributo della sociologia alla cultura e alle scienze umane, essendo infinite le sfaccettature che tale disciplina può assumere; Jean-Jacques Simard descrive 
le angosce e le conseguenze sociali della Révolution tranquille; Marcel Rioux traccia la differenza tra critica sociologica e sociologia asettica, le quali si occupano di campi d'indagine totalmente opposti; Nicole Laurin delinea il ruolo delle donne negli studi di sociologia; Céline Saint-Pierre e Michel Freitag, infine, espongono le problematiche attuali delle scienze umane e sociali, prima fra tutte la necessità impellente di normative che diano loro uno statuto.

2 Forse concepito più per un pubblico specializzato che occasionale, Sociologie et valeurs è un testo innovativo e per nulla scontato, curato nei dettagli da Gilles Gagné e JeanPhilippe Warren, i quali accompagnano ogni saggio con una presentazione dell'autore, un'introduzione alla sua opera, un riassunto e una minuziosa bibliografia. L'insieme costituisce una guida interessante per comprendere l'evoluzione del pensiero sociologico quebecchese. 